\title{
Effect of Concentric Braces on the Behaviour of Steel Structure by Pushover Analysis
}

\author{
Chetan Jaiprakash Chitte \\ M. Tech. (Structural Dynamics \& Earthquake Engineering) \\ Asst. Professor, R.C.Patel Institute of Technology, Near Nimzari Naka, Shirpur-425405, Dist. Dhule, \\ Maharashtra, India
}

\begin{abstract}
Today is the era of economy with the safety of the occupants/user. The past experiences of the earthquakes and the devastations restrict the designer towards the safety, rather than to achieve the economy in the construction. This has led the designers to move towards the performance based design of the structure and the pushover analysis is the part of that. Nonlinear static analysis, or pushover analysis, has been developed over the past twenty years and has become the preferred analysis procedure for design and seismic performance evaluation purposes, as the procedure is relatively simple and considers post elastic behavior. Beside all this, it has been observed that the bracings, if provided, in the structure, increase the capacity of the structure. There are various types of bracing being used wide over. Hence, in this paper, the effect of various types of concentric braces on the behavior of the structure is tried to be evaluated by using pushover analysis which can be used with due achievement of the economy taking care of safety.
\end{abstract}

\section{Introduction:}

Nonlinear static analysis, or pushover analysis, has been developed over the past twenty years and has become the preferred analysis procedure for design and seismic performance evaluation purposes, as the procedure is relatively simple and considers post elastic behavior. Pushover analysis is basically a step-by-step plastic analysis for which the lateral loads of constant relative magnitude are applied to a given structure and progressively increased until a target displacement is reached, while gravity loads are kept constant. The seismic risk may be reduced by taking special measures based on the scientific knowledge about the structural behavior of structure and earthquake action. Thus, as per seismic design philosophy, (a) a structure should not be damaged in the event of minor earthquake, (b) while limited structural damage is allowed in case of moderately strong earthquake even though nonstructural damage may be significant, and (c) in the event of an earthquake of higher intensity or strong earthquake, the structure may be damaged significantly without its collapse, so that human life may be saved in any case. Inelastic static analysis, or pushover analysis, has been the preferred method for seismic performance evaluation due to its simplicity. There are three different methods for performing pushover analysis, the capacity spectrum method (ATC 40), the displacement coefficient method (FEMA 273) and secant method (City of Los Angeles, Division 95).The pushover analysis procedure employing the capacity spectrum method delineated in ATC 40 is used.

\section{Braced frames:}

Braced framing systems resist lateral loads primarily by developing high axial forces in selected framing members .Only a small (or zero) percentage of the imposed lateral load on a braced frame is resisted by flexural or bending actions in moment-resisting connections. Braced framing systems proved popular in regions of high seismicity because materials savings could be achieved with respect to moment-resisting frames and control of frame drift due to high earthquake-induced inertial forces could be efficiently realized. Braced frames may generally be categorized as,

a. Concentric Braced Frames (CBFs)

b. Eccentric Braced Frames (EBFs)

\section{Concentric Braced Frames (CBFs):}

The concentric braced frame (CBF) is lateral force-resisting system that is characterized by high elastic stiffness. High stiffness is achieved by the introduction of diagonal bracing members that resist lateral forces on the structural frame by developing internal axial actions and relatively small flexural actions. Diagonal bracing members and their connections to the framing systems form the core units of a CBF. Braces can be of any standard sections, or can be formed by I-shaped sections, circular or rectangular tubes, double angles stitched together to form a T-shaped section, solid T-shaped section, single angles, channels, and tension-only rods and angles. Braced connections to the framing system are commonly composed of gusset plate with bolted or welded connections to the braces. Common CBF configurations are presented in the following figures. In 
general, the single diagonal (tension or compression), X-braced, chevron-braced (inverted V-shaped), V-shaped frames may be categorized as CBFs.

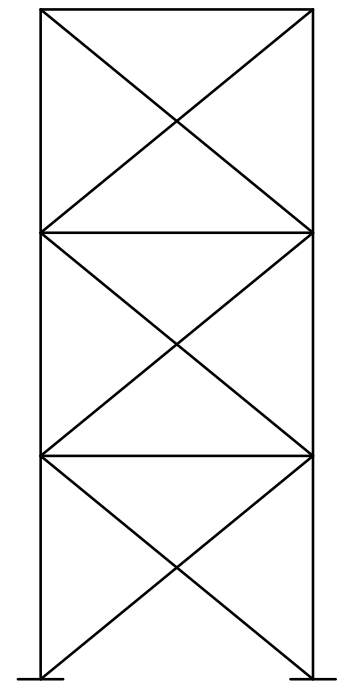

X- Braced CBF

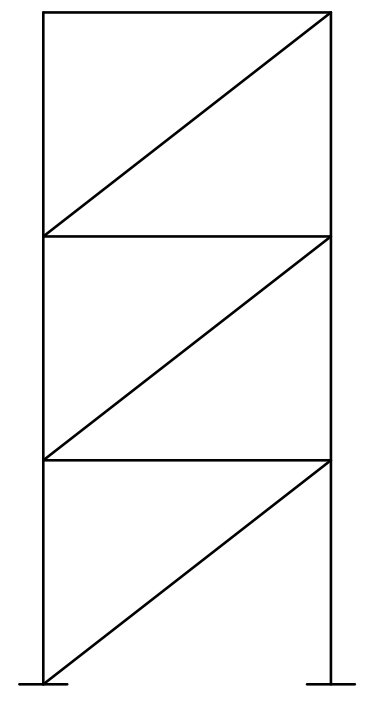

Diagonal Braced CBF

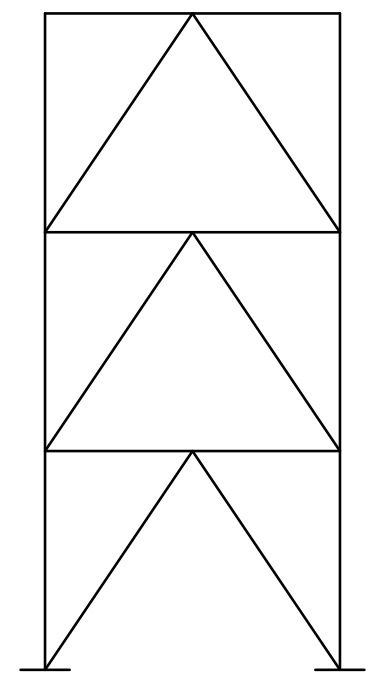

Chevron type CBF

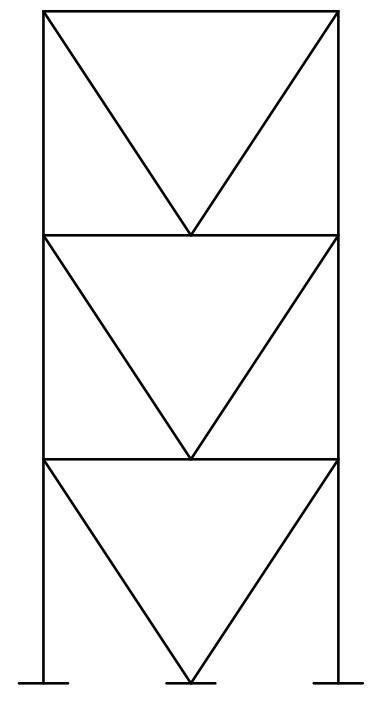

V- Braced CBF

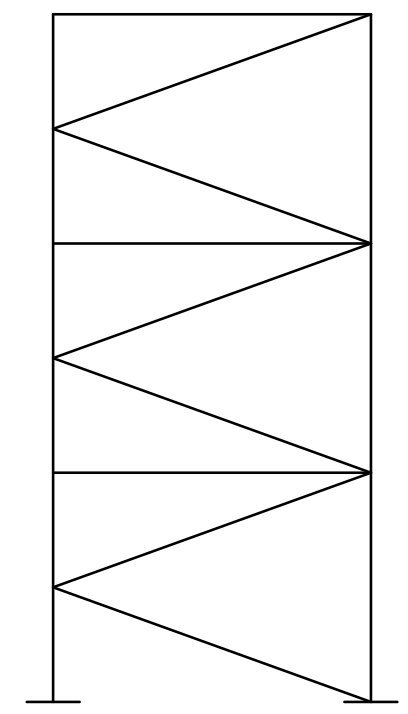

K- Braced CBF

Effect of Different Types of Bracing Configurations:

To evaluate the effect of different types of bracings, the following problem is analysed using SAP2000NL. Following bracing configurations are used:
1. With No Brace
2. With Tension Brace
3. With Compression Brace
4. With X-Brace
5. With Chevron Brace 


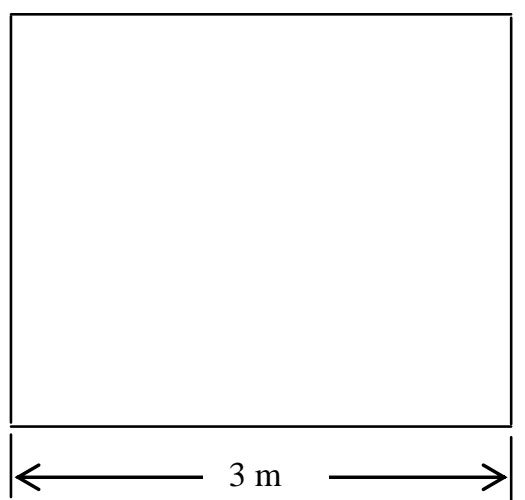

Plan
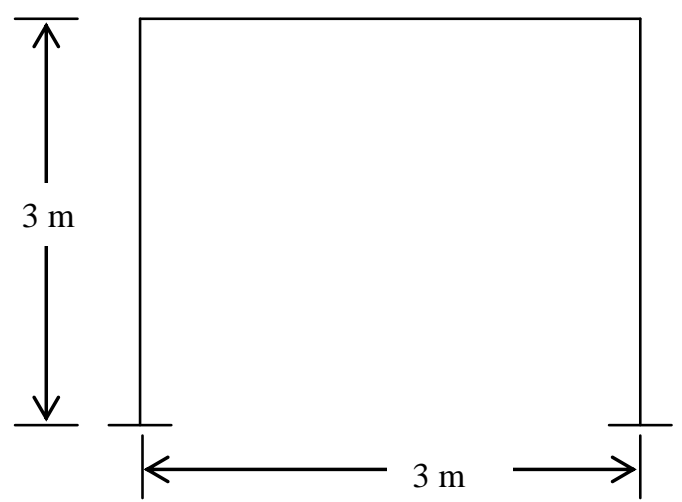

Elevation

\section{Plan and Elevation of Steel Building under Consideration}

\section{General Data:}

Seismic Data:

$$
\begin{aligned}
& \text { Thickness of RCC slab }=125 \mathrm{~mm} \\
& \text { Imposed load on roof }=0.75 \mathrm{kN} / \mathrm{m}^{2} \\
& \text { Floor finish }=1 \mathrm{kN} / \mathrm{m}^{2}
\end{aligned}
$$

Zone III, Zone factor $\mathrm{Z}=0.16$,

Importance factor $\mathrm{I}=1.5$,

Response reduction factor $\mathrm{R}=5.0$,

Soil type $=$ Medium soil.

\section{Table - Schedule of Sections:}

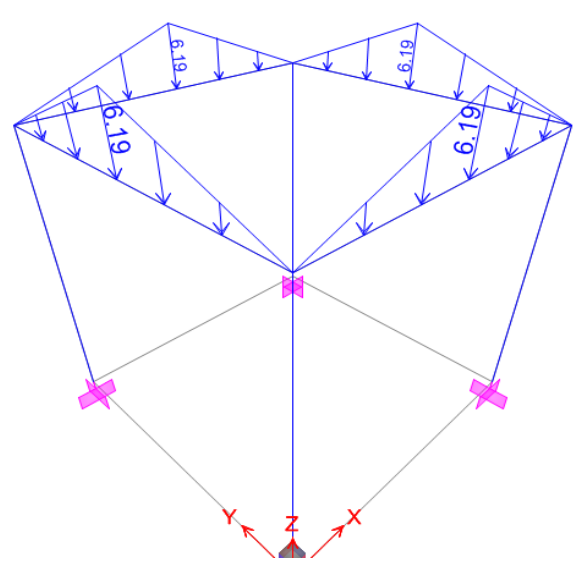

Dead Load on Frame

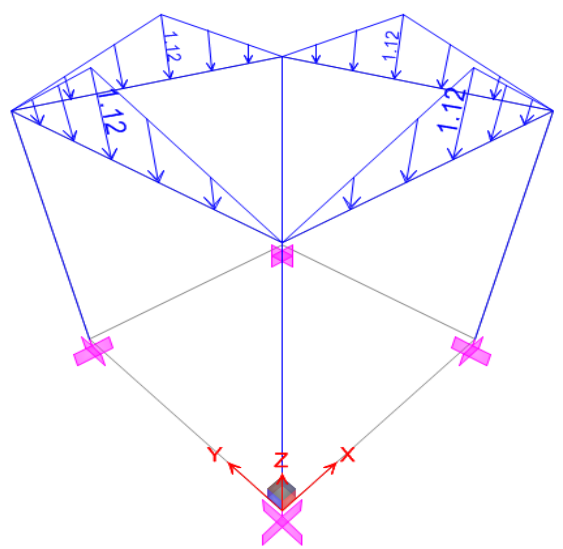

Imposed Load on Frame

Dead Load and Imposed Load on Frame 
Pushover curves for different cases are as shown below

(1) With No Brace:

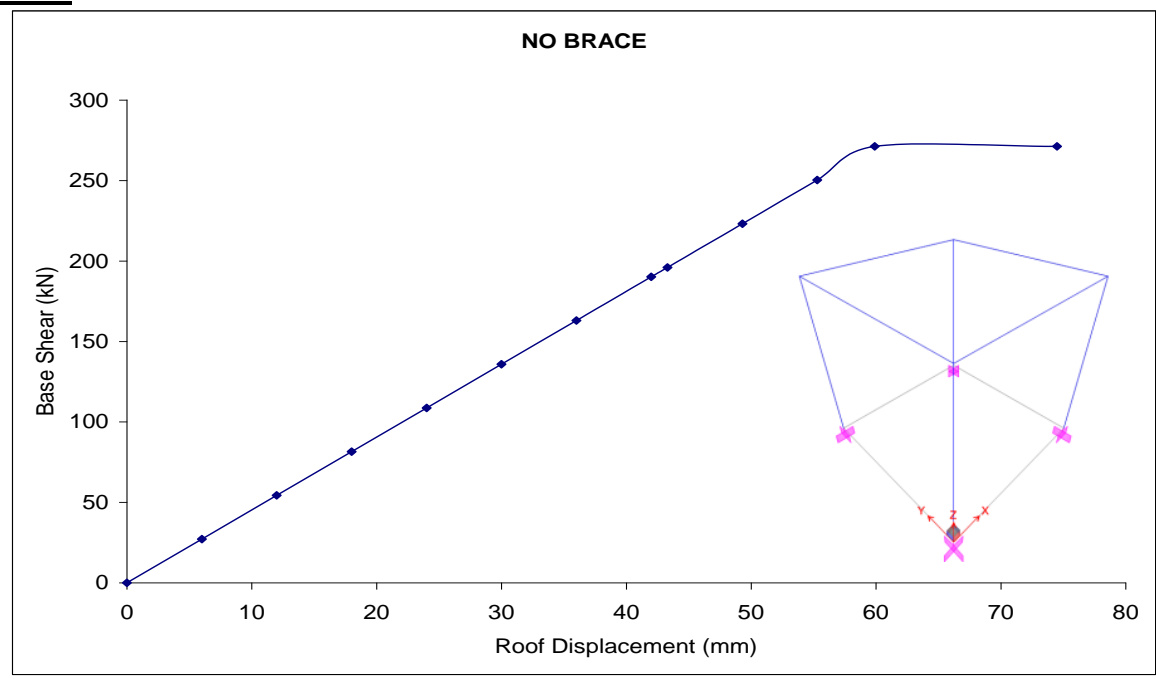

Capacity Curve for No Brace

(2) With Tension Brace:

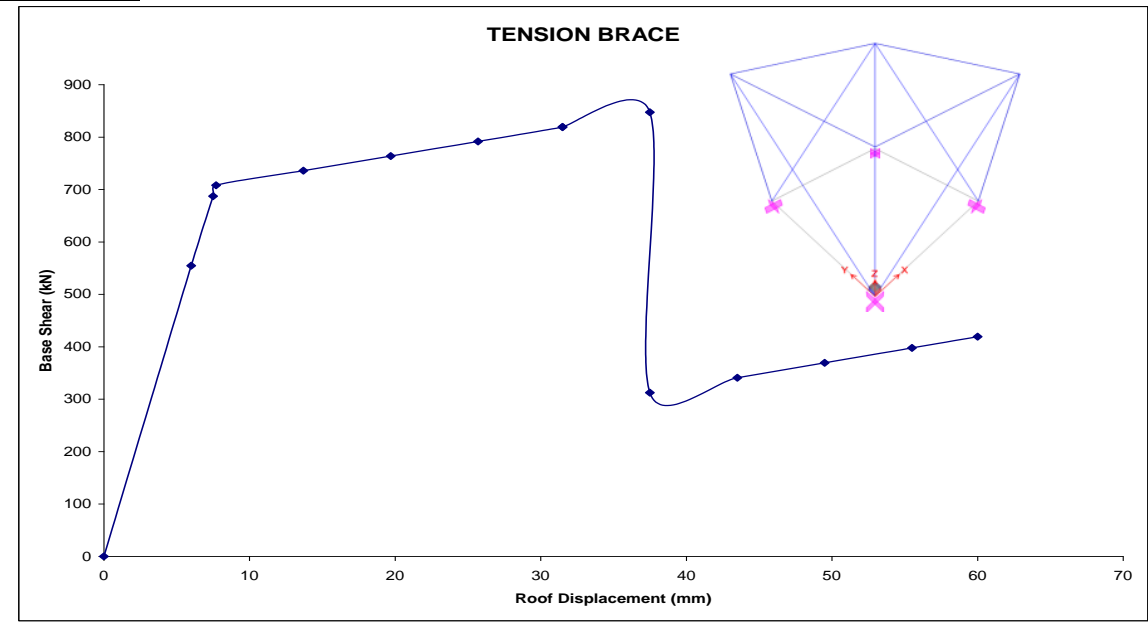

(3) With Compression Brace:

Capacity Curve for Tension Brace

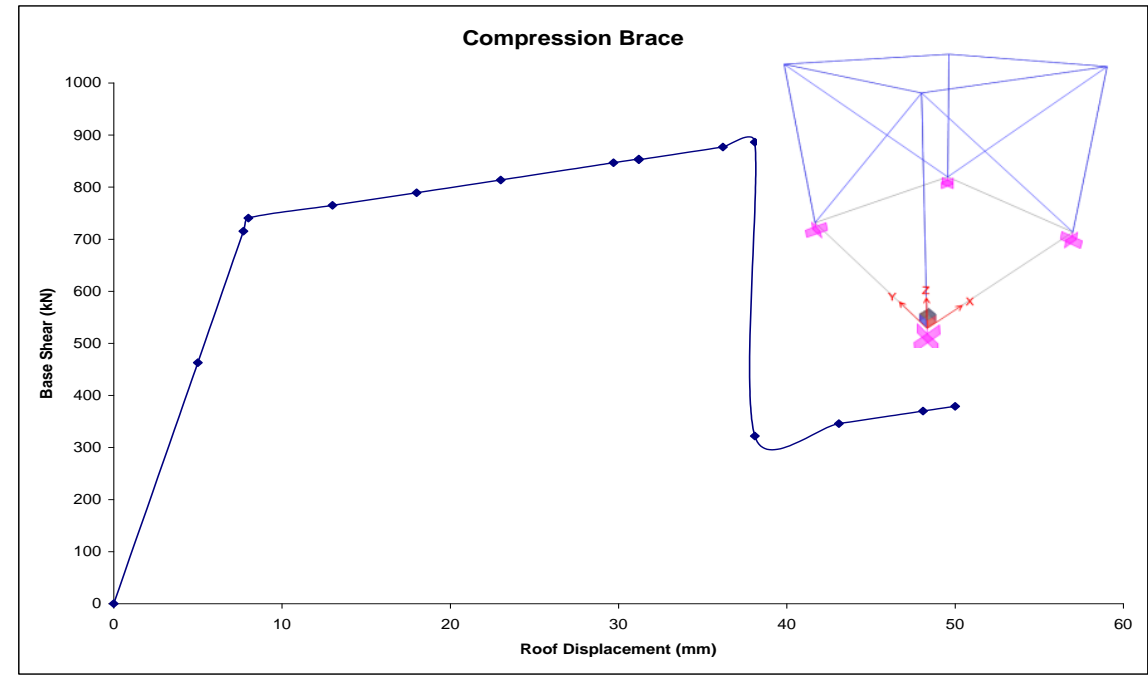

Capacity Curve for Compression Brace 
(4) With X-Brace:

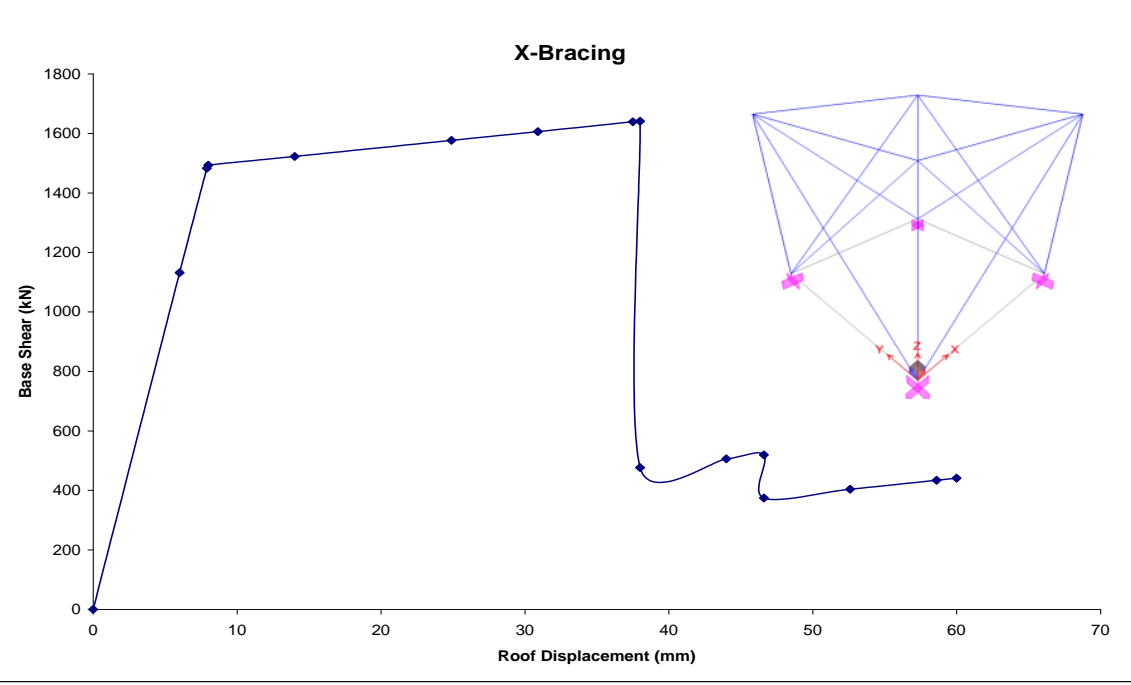

Capacity Curve for X-Brace

(5) With Chevron Brace:

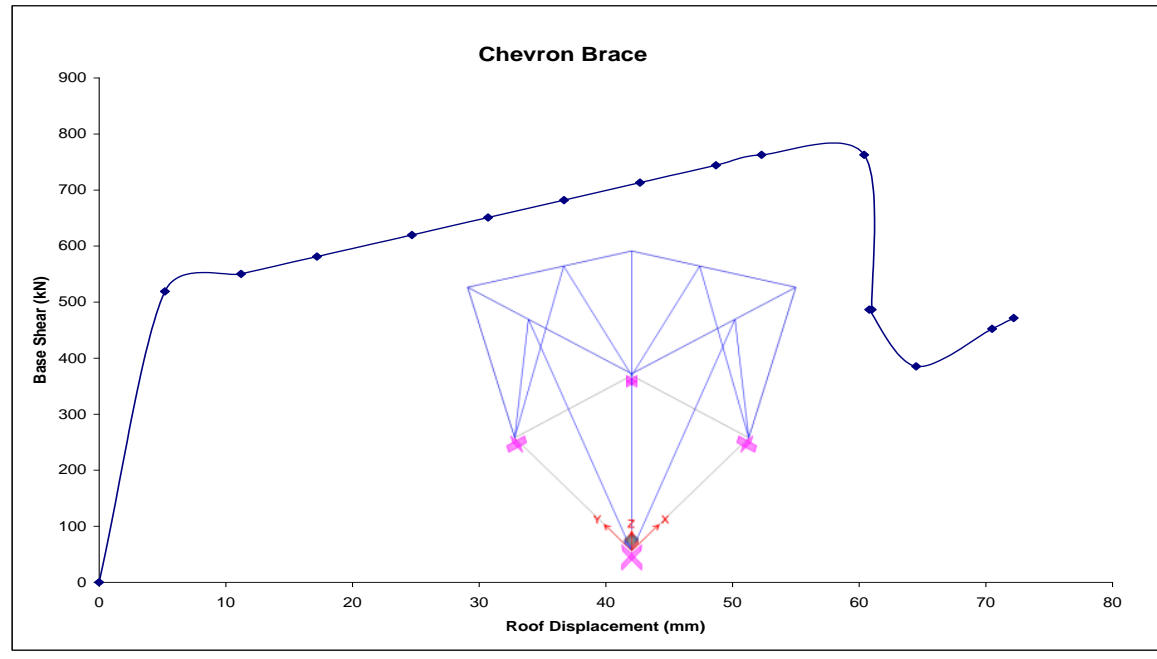

Capacity Curve for Chevron Brace

(6) Combined Response:

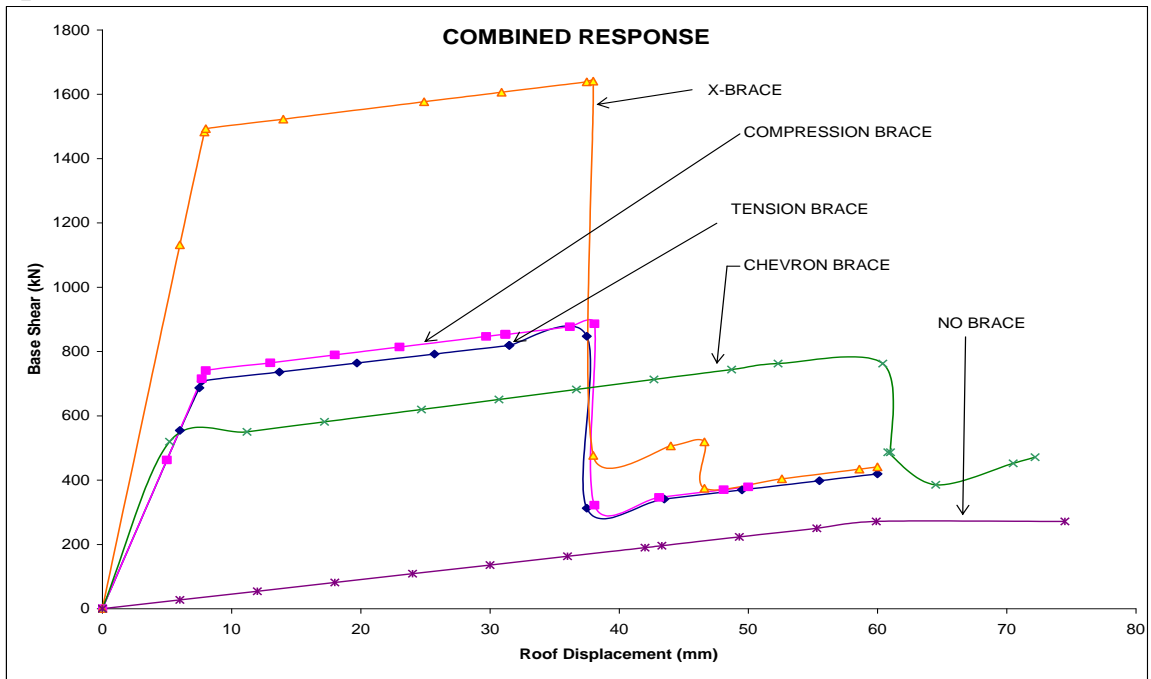

Capacity Curves for all Types of Braces 


\section{Conclusions:}

The capacity curves for all types of Braces states that the capacity of the structure is increased by applying the braces. By using the braces the capacity of structure to withstand an earthquake can be increased, but due consideration shall be given to the ductility of the structure. When tension or compression brace is used, the capacity as well as ductility nearly remains same, also when X-brace is used it gives the highest capacity but comparatively less ductility. The chevron type of brace gives moderate performance during an earthquake, since the capacity and ductility both are achieved.

\section{References:}

[1]. ATC, "Seismic Evaluation and Retrofit of Concrete Buildings", Volume- 1.Applied Technology Council (Report No.40), Redwood City, California (1996)

[2]. Bruneau M.,Uang C.M.Whittaker A., "Ductile Design of Steel Structures", McGraw -Hill Publications

[3]. FEMA, "NEHRP Guidelines for the Seismic Rehabilitation of Buildings", Developed by the Building Seismic safety Council for the Federal Emergency Management Agency (Report no. FEMA-273), Washington D.C., (1997)

[4]. Habibullah A, and Pyle S., "Practical Three Dimensional Nonlinear Static Pushover Analysis", Structures Magazine, Winter (1998)

[5]. IS: 800-1984(Reaffirmed 1998),IS 800(Draft),Indian Standard, “ Code of Practice for General Construction in Steel",(Second Revision). Seventeenth Reprint MAY 2000

[6]. IS 1893 (Part 1):2002,Indian Standard, “Criteria for Earthquake Resistant Design of Structures", PART 1-General Provisions and Buildings(Fifth Revision)

[7]. Mahin Stephen and Uriz PAtxi , "Performance-Based Seismic Design of Steel Braced Frame Buildings" (2004)

[8]. SP(6):1972, ISI Handbook for Structural Engineers, "6.Application of Plastic Theory in Design of Steel Structures". Indian Standards Institutions 